\title{
Enlightenment from the Education Mode of Rong-Tai Academies of Qing Dynasty on the Moral Education of Contemporary Universities*
}

\author{
Liqin Fan \\ Office of Academic Research \\ Minjiang University \\ Fuzhou, China 350108
}

\begin{abstract}
Ancient Chinese academies contain rich moral education resources. The educational tenets of "sages" and educational thought of "cultivating one's character and being good" and the schooling idea of "respecting the classics and valuing history for practical use" passed down by Rong-Tai Academies of Qing Dynasty have provided beneficial enlightenment to the tenets and the content of moral education, the curriculum and the compilation of teaching materials of contemporary universities.
\end{abstract}

Keywords - academy education; contemporary university; moral education

\section{INTRODUCTION}

Moral education refers to the education of students' ideological, political, moral and psychological quality, while the narrow sense of moral education refers to the education of moral quality. The ancients said, "for people, character is the master of talent, and talent is the slave of character." Moral character is a person's soul and the source of all trees. Without moral character, there is no foundation of standing. Therefore, moral education plays an indispensable role in the whole education system. With the development of social history, moral education develops and changes, but its principles, contents and methods have certain commonality, so moral education can be inherited.

Academy was an important form of educational organization in ancient China, which has many functions such as lecturing, sacrificing, collecting books and carving books. Academy education paid attention to moral education, opposed the pursuit of fame and wealth, stressed respecting teachers and students, and academic freedom, and advocated academic innovation. It always adheres to the educational thought of Confucianism and takes the achievement of moral personality as the ultimate goal, which is the most dynamic and academic part of traditional higher education in China. Chinese Academy Education has played an important role in the educational and academic history of our country, and its moral education experience cannot be ignored in the contemporary university moral education. This paper takes

*Fund: education research project for young and middle-aged teachers in Fujian in 2018 (Project No.: JAS180376). the education mode of Rong-Tai Academies of Qing Dynasty as an example to explore its enlightenment to the contemporary moral education in universities.

\section{ENLIGHTENMENT FROM THE EDUCATIONAL TENET OF “To Be A SAGE” OF RONG-TAI ACADEMIES IN THE QING}

\section{DYNASTY}

\section{A. The Connotation of the Educational Tenet of "To Be A Sage" of Rong-Tai Academies in the Qing Dynasty}

In the Qing Dynasty, the education of Rong-Tai Academies fully reflected the educational tenet and idea of "to be a sage". Chen Shouqi's "Eight Rules of Aofeng Chongzheng Lecture Hall" said: "learning is to change a man into a sage" and "scholars shall have the concept of being upright and bearing the burden of the world" ${ }^{1}$. The educational tenet and concept of "to be a sage" in academy education were fully reflected in the academic rules of RongTai Academies in Qing Dynasty. There were many words such as "sages" and "saints" in the academic rules of the academy, and examples of sages' behavior were also listed to encourage students to follow them. For example, "an act of righteousness, regardless of life was written in the biography of sage" ("Academic Agreement of Dazhongcheng Jueluoman Gongbao"); students should "read books of sages

\footnotetext{
Unless otherwise noted, the source of the academic rules cited in this paper is from the following editions: "Affairs of Aofeng Academy" (1822) by Chen Shouqi of Qing Dynasty, cited from Volume 10 of "Zuohai Anthology", published in Jiaqing period of the Qing Dynasty; "Academic Rules of Baisha Academy" (1811) by Yang Guisen of Qing Dynasty, quoted from Volume 4 of "Zhanghua County Annals" in Daoguang period of Qing Dynasty, No. 13 of "Chinese Local Annals Series"; “Academic Rules of Haidong Academy assigned by Taiwan Daojian Academic Governor and Xuezheng Jueluo Si Mingle", quoted from Volume 8 of "Renewal of Taiwan Chronicles", the first series of "Historical Documents of Taiwan"; "Eight Rules of Aofeng Chongzheng Lecture Hall” (1825), "To All Students of Aofeng Academy" (in Daoguang period of Qing Dynasty) and "Academic Agreement of Dazhongcheng Jueluoman Gongbao" by Chen Shouqi of Qing Dynasty, "Academic Rules of Haidong Academy" (1740) by Liu Liangbi of Qing Dynasty, "Academic Rules of Wenshi Academy" (1766) by Hu Jianwei of Qing Dynasty, and "Eight Rules of Wenshi Academy" (in Guangxu period of Qing Dynasty) by Lin Hao of Qing Dynasty, all from “Academic Rules of Chinese Academies", Hunan University Press, 2000.
} 
on a daily basis" (Chen Shouqi's "To All Students of Aofeng Academy"); "take behaviors of sages as standard of conduct" ("Academic Agreement of Dazhongcheng Jueluoman Gongbao"). One shall not only follow the behaviors of sages but also learn from their words and put the words into action. According to Liu Liangbi's "Academic Rules of Haidong Academy", "the establishment of the academy was originally based on the cultivation of talents". According to "Academic Rules of Haidong Academy assigned by Taiwan Daojian Academic Governor and Xuezheng Jueluo Si Mingle", "sages have an everlasting name because of their character", "take sages as example" and "take actions according to words of sages". In Hu Jianwei's "Academic Rules of Wenshi Academy", "To be a sage is the highest ethnics for people" (quoted from Mencius); "the way to develop to be a sage"; "put words of sage into action" (quoted from Mencius); "scholars shall read classic books and then investigate the behaviors of sages". In "Academic Rules of Baisha Academy", Yang Guisen of Qing Dynasty said: "all words of sages are to teach us to be filial to our parents and respect the elders"; "then one will be at the position of sage. Every man can become a sage." "One can be a sage with a good heart". In "Affairs of Aofeng Academy", Chen Shouqi said the theory of "to be a sage". In his "Eight Rules of Aofeng Chongzheng Lecture Hall", he said: learning is to change a man into a sage" and "sages respect sage and common people". In Lin Hao's "Eight Academic Rules of Wenshi Academy", there are also statements of "predecessors", "sages" and "following words of sages of the time (quoted from Confucianism)". They all showed that they respected and honored sages and taught students by taking sage as example, and implicitly encouraged students to take sages as their highest learning model, to develop in the direction of sages, and finally become sages.

\section{B. Enlightenment on the Moral Education Aim of Contemporary Universities}

With regard to the purpose of traditional Chinese education, "Daxue" said: "the way of education is to help people know good and evil, become a new man and keep on doing good things" [1]. It means that the ultimate goal of education is to keep people "doing good things". In "Yan Zi's Suohao and Xuelun", Cheng Yi of the Northern Song Dynasty said: "learning help people know the way of sages" [2]. In "Academic Rules of Donglin Academy", Gu Xiancheng of Ming Dynasty said: "the state has set up academy to help people become sages." [3]. The education aims of Rong-Tai Academies of Qing Dynasty has made a more profound interpretation of the purpose of traditional Chinese education, which is to make people become sages. The original meaning of sage is the combination of saint and person of virtue. Later, it is generally called people with noble morality and extraordinary intelligence. The educational tenets of "to be a sage" of Rong-Tai Academies of Qing Dynasty have important implications for the establishment of the tenets of moral education in contemporary universities.

For one thing, it shall aim "to be a sage" in guiding ideology. In a narrow sense, the moral education of contemporary universities specifically refers to the moral quality education of college students. The moral quality education is an education for the observation of social merits and the cultivation of civilized behavior habits. Its educational purpose is to make people become moral noble people and "sages". College students are the builders and successors of the future of the country. Their moral quality is directly related to the spiritual civilization establishment of the future country. Without morality, people even if they are knowledgeable and capable, cannot become men beneficial to the society. Therefore, the guiding ideology of moral education in contemporary university should attach importance to the education of "to be a sage", emphasize the education of moral quality, the molding of noble soul, and to be a moral noble person first.

For the other thing, it is necessary to respect "sages" and take "sages" as an example in practice and put words of "sage" into action. The moral education in contemporary universities should not stop at the oral level, but should help students learn ways of "sages" and put words into action and set "sage" as example through the courses of "sage" education, so that students can practice it in real life and become the support for the development of country.

\section{ENLIGHTENMENT FROM THE EDUCATION THOUGHT OF "CUltivating ONE's CHARACTER AND BEING GOOD” OF RONG-TAI ACADEMIES OF QING DYNASTY}

\section{A. The Connotation of the Education Thought of "Cultivating One's Character and Being Good" of Rong-Tai Academies of Qing Dynasty}

The education of Rong-Tai Academies of Qing Dynasty reflected the educational thought of "cultivating one's character and being good" and the idea of taking selfcultivation as "the purpose of learning" before learning knowledge. Lin Hao's "Eight Rules of Wenshi Academy" says: "by reciting text, learning from sage and writing words, students encourage each other from day to day and learn to be good. One day they can be the pillar of the country". In "Eight Rules of Aofeng Chongzheng Lecture Hall", Chen Shouqi also taught students to cultivate their character and be good. He said: "why should a man study in academy? The purpose is to help him know good and evil and learn to be a good man. He should learn how to cultivate his character and be good at this way, so that he can know justice and interest, good and bad, and honor and disgrace, set up a positive goal, practice personally, and make friends widely but carefully". It can be seen that one who cultivate his character and be good shall first "know justice and interest" and "know good and bad", "set up a positive goal", "know honor and disgrace", "practice personally", "make friends widely but carefully" and "do not litigate". To be specific, "to know justice and interest" means to select justice and interest in a strict and correct way. According to Yang Guisen's "Academic Rules of Baisha Academy", "the best way to build one's character is to help him select justice and interest in a strict and correct way. Why do Bo Yi and Shu Qi last through the ages? It is because they can choose justice and interest in a strict and correct way, and they don't change 
their character even if they die. "To know good and bad" needs one to know the boundary. In "Eight Rules of Aofeng Chongzheng Lecture Hall", Chen Shouqi also taught students that: "one associating with an evil person shall be rebuked" and "one cannot connect with evil person, or may be influenced". "To set a positive goal" requires students to establish lofty aspirations when they entered the school. Aofeng Academy's "Academic Agreement of Dazhongcheng Jueluoman Gongbao" says: "in terms of ambition, one shall set up a positive goal at the beginning of enrollment. With lofty aspirations and setting sage as example, one shall do things by oneself and not take to the woods". "To know honor and disgrace" requires students to "be shamesensitive". In the third article of "To All Students in Aofeng Academy", Chen Shouqi specially stated: "the reason why people are human is that they have a sense of shame" and the importance of the four cardinal virtues: humanity, justice, propriety and wisdom in the cultivation of character in order to show the importance of "sense of shame" in one's life. Then, the negative examples are given to illustrate the harm of people without the sense of shame. The positive examples are "ancient sages with sense of shame", such as Yi Yin, Bo Yi and Liu Xiahui, to set up a model for students to follow. At last, the students were advised to "know the sense of shame" and told them "no man can be a sage without the sense of shame". "To practice personally" requires students to do things personally. In "Academic Rules of Wenshi Academy", Hu Jianwei quoted the statements of Lv Hui, an official of Northern Song Dynasty, "it is not necessary to read much, read a word, and do a word", and Yichuan Chengyi, "reading a lot is inferior to do a little", to show the importance of personal practice. "To make friends widely but carefully" requires student to be willing to communicate with their classmates in their study, but they also need to be cautious in making friends. For example, "Academic Agreement of Dazhongcheng Jueluoman Gongbao" says: "students need to make friends widely. It is unwise to be a lone ranger". In "Eight Rules of Aofeng Chongzheng Lecture Hall", Chen Shouqi also reminded students "to make friend carefully". He said: "gentlemen shall be cautious in making friend. A good friend can help too much, while a bad friend may destroy one's character. "Do not litigate" requires students that do not like litigation in everything. In $\mathrm{Hu}$ Jianwei's "Academic Rules of Wenshi Academy", the people who like litigation are generally "mean, mechanical and deceitful". "Only a few litigations are needed". There are three bitters in litigation. After the final trial, "the whole things come to obvious, the result usually is not good", which has no advantage. Therefore, it is advised that all students should "read clearly and rationally and have a peaceful mind". "If someone offend us or do something bad to us purposely, we should rebuke them emotionally and forgive them rationally", and thus "bury the hatchet". Only when it is absolutely necessary to "appeal to the chief officer", it is possible to "write a bill of complaint according to the matter".

\section{B. Enlightenment on the Content of Moral Education in Contemporary Universities}

In a narrow sense, the content of moral education in contemporary universities specifically refers to moral quality education. The moral quality education of contemporary universities should fully absorb the essence of Chinese traditional moral education. The education of Rong-Tai Academies of Qing Dynasty has provided a good example for the content of moral education in universities, and it has an important inspiration for the content of moral education in contemporary universities.

First, moral education in contemporary universities should be based on people and cultivate talents with both ability and morality. The education of Rong-Tai Academies of Qing Dynasty was aimed at cultivating talents with both ability and morality. It was required to put "morality" first. Students shall "know justice and interest", "know good and bad", "practice personally" "make friend widely but carefully" and "do not litigate". For example, the academic rule of Rong-Tai Academies of Qing Dynasty required students to "know justice and interest". It is very important for it is related to the character of one man and it is the most important point in one's character, and the standard to distinguish gentleman and vile person. "To judge a man is according to his selection of justice or interest" (Aofeng Academy's "Academic Agreement of Dazhongcheng Jueluoman Gongbao"), and it's also the first thing for a person to "establish a good character".

Second, the contemporary moral education of university should pay attention to ideal education and promote college students to set up a positive goal early. At present, the ideal of college students includes the realization of the great ideal of communism and the realistic ideal of building a strong socialist country. The ideal is the spiritual pillar of our study and life. To realize the ideal, one must first make up his mind. The academic rule of Rong-Tai Academies of Qing Dynasty requires students to "set up a positive goal". It required students to set up a positive goal early and correct their aspirations. It has been regarded as the first essence of morality since ancient times. In "Zuo Zhuan · 27th Xiang Gong Year", "to set up a goal is through words. Once words are spoken out, one must practice and be loyal to his words. Thus, he can make determination to achieve it without hesitation" [4]. In addition, students shall have positive ambition and correct motives, and then make progress gradually. With wisdom and understanding, one can have "great success". And ambition is "the place where the heart goes from". Scholars with ambition are just like archers with goals. Students should not only have a goal, but also pay attention to motive. If the goal is not correct, there is no way to make a difference. According to $\mathrm{Hu}$ Jianwei's "Academic Rules of Wenshi Academy", "in terms of correcting ambition, one shall know it is the place where the heart goes from. If a man makes a determination, he/she must first know where he/she want to achieve and then can start along the direction. If a traveler wants to go to the east, he must first go to the east. If a traveler wants to go to the west, he must first go to the west. The shooter shall know the target, so do learners. No students without goals truly make a difference. 'The 
part essay, Shitie and calligraphy in line with the traditional ethical standards to cultivate the basic writing ability.

ambitions of sages for first year"'

Third, the contemporary moral education in universities should pay attention to the use of scientific and reasonable methods, the role of practice, and the practical application of moral education. The traditional moral education is usually in the form of teacher's explanation, instruction and sermon. This kind of education method often makes it difficult for students to absorb deeply, and even produces a rebellious and confrontational psychology. Therefore, the contemporary moral education in universities should strengthen the practicality, change the passive acceptance of students to active participation, and have some feelings and touches in the independent learning. Practice is the ancient saying of "to practice personally". The education of RongTai Academies of Qing Dynasty placed special emphasis on "personal practice". Hu Jianwei's "Academic Rules of Wenshi Academy" says: "it's not good to just say but not do it. All sages recorded in history have practiced what they say. So when people read books of sages they should not just take their speech as words but their actions. Just like Zhu Zi said: 'it is necessary to put words of sage into action'. One reads words of sage and follows them and practice personally, and then can become a sage too".

\section{ENLIGHTENMENT FROM THE LEARNING THOUGHT OF "RESPECTING CLASSICS AND VALUING HISTORY FOR PRACTICAL USE” OF RONG-TAI ACADEMIES OF QING DYNASTY}

\section{A. The Academic Connotation of "Respecting the Classics and Valuing History for Practical Use" of Rong-Tai Academies of Qing Dynasty}

The academic connotation of "respecting the classics and valuing history for practical use" of Rong-Tai Academies of Qing Dynasty was mainly embodied in the emphasis on the content of moral education. As a part of Chinese traditional Confucian education, the education of Rong-Tai Academies of Qing Dynasty mainly studied Confucian classics. First of all, the most important content of learning was classics and history. Chen Shouqi's "Eight Rules of Aofeng Chongzheng Lecture Hall" has the rule of "choosing classics". Aofeng Academy's "Academic Agreement of Dazhongcheng Jueluoman Gongbao" has the rule of "respecting classics". Liu Liangbi's "Academic Rules of Donghai Academy" has the rule of "admiring classics and history". Hu Jianwei's "Academic Rules of Wenshi Academy" has the rule of "reading classics and history". Lin Hao's "Eight Rules of Wenshi Academy" has the rule of "understanding the principles" and "knowing the history". They all concretely and clearly show the good tradition of respecting the classics and valuing the history in Rong-Tai Academies. Secondly, they also had the study of ancient poems and verses that embodies the traditional ethics and moral education. For example, it is required by the academy to read "the garden of culture", Qu Yuan's "Lisao", Wu Hou's "Biao", "Chunqiu", preface of "Maoshi", and poems of Su Shi, Li Bai, Tao Yuanming and Xie. Thirdly, they had the training of eight-

\section{B. Enlightenment on the Compilation of Moral Education Textbooks for Contemporary Universities}

It is a remarkable feature of Chinese traditional education to attach importance to ethical education. Zhang Qizhi said: "beginning from Confucius, Chinese Confucian education has formed a distinct spirit of humanism and values with ethics as the core, forming a tradition of attaching importance to moral education and quality cultivation. For example, restrain oneself and acting accords with 'rites'. Love people and things and taking 'rites' as conduct code. Take 'benevolence' as the highest standard and 'sage' as the highest goal of talent cultivation. After the baptism of 'deposing hundreds of schools and respecting Confucianism alone' in Han Dynasty, and the development of Neo Confucianism in Song and Ming Dynasty, these traditions of Confucian education have been solidified and strengthened continuously". Then he came to the conclusion that "moral education, the curriculum structure based on ethics, occupies a dominant position in the content of traditional Chinese education." [5] Moral education in contemporary universities should absorb the essence of Chinese traditional moral education, make full use of excellent resources of traditional Chinese culture and perfect the system of moral education in textbook compilation and curriculum setting. Rong-Tai Academies of Qing Dynasty clearly pointed out the excellent Confucian classics in the schooling thought of "respecting the classics and valuing history for practical use". For example, first of all, they should respect the Confucian classics. Chen Shouqi's "Eight Rules of Aofeng Chongzheng Lecture Hall" required to read biographies, origin of classics and the ladder of primary school, and listed the specific booklist. Secondly, it valued history. In the academic rules of Rong-Tai Academies of Qing Dynasty, the book called "Introduction to Science of History" was defined as the book that must be read by the students, and the book of "Braches of Historians" was defined as the book that the students were involved in, and the specific booklist was also listed. In addition, there were other readable books, such as the books of Zhou, Qin, Han, Wei and Jin, the five books of Song Dynasty and the Confucian works of Yuan and Ming Dynasties, all of which are collected by scholars. It is emphasized that respecting the classics and valuing the history can make people become "great scholar" of "understanding the truth and mastering the knowledge", so as to achieve the purpose of "becoming a man of talent", "knowing the people and discussing the world" and "for practical use". Therefore, the compilation of contemporary college moral education textbooks should make full use of the above excellent traditional Chinese cultural classics, and integrate them into the ideological and political education and patriotism education, so as to make moral education textbooks lively and rich in connotation.

\section{CONCLUSION}

In a word, the moral education in contemporary universities should not be limited to the stories of 
contemporary martyrs, but should fully absorb the spirit of traditional Chinese culture and improve the moral education system. On the whole, the education of Rong-Tai Academies of Qing Dynasty is a comprehensive and perfect education ideological system, which undertakes the important mission of cultivating talents, inventing the holy way and continuing the orthodoxy. It has not only the schooling tenet and idea of "becoming sage and saint", but also essence of education thought of "cultivating one's character and being good", such as "know justice and interest, good and evil, and disgrace and honor, and set up a positive goal", "practice personally", "make friends widely but carefully" and "do not litigate", and the schooling though of "respecting classic and valuing history for practical use". The education of Rong-Tai Academies of Qing Dynasty was not only an important part of the ancient academy education, but also a summary of the academy education theory and practical experience. Therefore, under the background of actively carrying forward the traditional education and teaching reform, it is of great significance to explore the contemporary university moral education based on the education mode of Rong-Tai Academies of Qing Dynasty. It is suggested to fully tap its profound connotation to serve the contemporary university moral education.

\section{REFERENCES}

[1] (Song) Zhu Xi. Notes on Chapters and Sentences of Four Books. Beijing: Zhonghua Book Company, 1983: 3. (in Chinese)

[2] (Qing) Huang Zongxi's Original Work, (Qing) Quan Zuwang's Revision. Study Plan of Song and Yuan Dynasties (Vol. 16). Beijing: Zhonghua Book Company, 1982: 642. (in Chinese)

[3] (Ming) Gu Xiancheng. Donglin Huiyue. Deng Hongbo. Academic Rules of Chinese Academies. Changsha: Hunan University Press, 2000: 13. (in Chinese)

[4] (Jin) Noted by Du Yu, translated by (Tang) Kong Yingda. Translation of Chunqiu andn Zuozhuan (Vol. 38). Shanghai: Shanghai Ancient Books Publishing House, 1990: 1996. (in Chinese)

[5] Zhang Qizhi. Introduction to Chinese Culture. Beijing: Beijing Normal University Press, 1994: 194. (in Chinese) 